\title{
Hormonal response to lipid and carbohydrate meals during the acute postprandial period
}

\author{
Rick J Alleman Jr and Richard J Bloomer
}

\begin{abstract}
Background: Optimizing the hormonal environment during the postprandial period in favor of increased anabolism is of interest to many active individuals. Data are conflicting regarding the acute hormonal response to high fat and high carbohydrate feedings. Moreover, to our knowledge, no studies have compared the acute hormonal response to ingestion of lipid and carbohydrate meals of different size.

Methods: We compared the hormonal response to lipid and carbohydrate meals of different caloric content during the acute postprandial period. Nine healthy men ( $22 \pm 2$ years) consumed in a random order, cross-over design one of four meals/beverages during the morning hours in a rested and fasted state: dextrose at $75 \mathrm{~g}$ (300 kcals), dextrose at $150 \mathrm{~g}$ (600 kcals), lipid at $33 \mathrm{~g}$ (300 kcals), lipid at $66 \mathrm{~g}$ (600 kcals). Blood samples were collected Pre meal, and at $0.5 \mathrm{hr}, 1 \mathrm{hr}, 2 \mathrm{hr}$, and $3 \mathrm{hr}$ post meal. Samples were assayed for testosterone, cortisol, and insulin using ELISA techniques. Area under the curve (AUC) was calculated for each variable, and a $4 \times 5$ ANOVA was used to further analyze data.

Results: A meal $x$ time effect $(p=0.0003)$ was noted for insulin, with values highest for the dextrose meals at the $0.5 \mathrm{hr}$ and $1 \mathrm{hr}$ times, and relatively unaffected by the lipid meals. No interaction $(p=0.98)$ or meal $(p=0.39)$ effect was noted for testosterone, nor was an interaction $(p=0.99)$ or meal $(p=0.65)$ effect noted for cortisol. However, a time effect was noted for both testosterone $(p=0.04)$ and cortisol $(p<0.0001)$, with values decreasing during the postprandial period. An AUC effect was noted for insulin $(p=0.001)$, with values higher for the dextrose meals compared to the lipid meals $(p<0.05)$. No AUC effect was noted for testosterone $(p=0.85)$ or cortisol $(p=0.84)$.

Conclusions: These data indicate that 1) little difference is noted in serum testosterone or cortisol during the acute postprandial period when healthy men consume lipid and dextrose meals of different size; 2) Both testosterone and cortisol experience a drop during the acute postprandial period, which is similar to what is expected based on the normal diurnal variation-feeding with lipid or dextrose meals does not appear to alter this pattern; 3) dextrose meals of either $75 \mathrm{~g}$ or $150 \mathrm{~g}$ result in a significant increase in serum insulin, in particular at 0.5 hr and 1 hr post-ingestion; 4) lipid meals have little impact on serum insulin.
\end{abstract}

\section{Background}

Many investigators have sought to elucidate the hormonal response to feeding, as such an understanding may provide insight into important biological processes that occur in the postprandial state. Both the meal size [1,2] and macronutrient type [3-5] may impact the hormonal response. Although this ensuing hormonal response may be important to a variety of individuals (e.g., diabetics, those with metabolic syndrome, those attempting to lose

\footnotetext{
* Correspondence: rbloomer@memphis.edu

Cardiorespiratory/Metabolic Laboratory, Department of Health and Sport Sciences, University of Memphis, Memphis, TN, USA
}

body weight), active individuals engaged in regular exercise appear particularly interested in this area [6]. This may be due to the fact that the hormonal response to feeding may be related to anabolism, which may have a direct impact on exercise training-induced adaptations (e.g., muscle mass gain, glycogen resynthesis). With this in mind, many active individuals have adapted feeding strategies in attempt to favorably alter the circulating levels of these hormones. Specifically, some active individuals choose to consume high carbohydrate meals [7]; although, recommendations also include the consumption

\section{Ciomed Central}


of high fat meals while restricting dietary carbohydrate $[8,9]$.

Although much literature exists with regards to the postprandial hormonal milieu, data are conflicting with regards to the hormonal response following the ingestion of carbohydrate- and lipid-rich food [4,10-17]. Moreover, to our knowledge, no studies have compared the acute hormonal response to ingestion of carbohydrate and lipid meals of different size.

The hormones that appear to receive the most attention within the athletic world, in particular as related to feeding, are insulin, testosterone, and cortisol. Insulin has multiple physiological functions, ranging from the stimulation of blood glucose uptake into cells [18] to protein anabolism [19]. It is well documented that insulin significantly increases following ingestion of a carbohydrate rich meal $[2,3,11,12,20]$, with more pronounced increases noted in those with impaired glucose tolerance [12]. Insulin has also been noted to increase following ingestion of a meal rich in saturated fat ( 40 grams) [13], unsaturated fat ( 26 grams) [12], and a ratio of saturated to unsaturated fat (52:59 grams) [17]. The above investigations included men with high fasting triglyceride levels (33 \pm 7 years), a combination of healthy men and men with metabolic syndrome (age range: 20 33 and 18-49 years, respectively), and healthy men (27 \pm 8 years), respectively. However, the insulin response to feeding has also been shown to be minimal when healthy men (age range: 20-25 years) ingest meals rich in saturated fats ( 45 grams) [15]. Clearly, the population tested, as well as the type and quantity of macronutrient, may influence the postprandial insulin response with regards to both carbohydrate and lipid meals.

Related to testosterone, a well-described anabolic hormone involved in muscle tissue growth, a diet that is chronically high in fat appears to increase endogenous testosterone production [21]. However, acute intake of dietary fat results in a reduction in total testosterone $[14,17]$. Comparable findings are noted with consumption of acute carbohydrate meals, a finding documented in healthy men and male patients with chronic obstructive pulmonary disease [10], as well as in healthy and obese women [11]. Similar, although insignificant, reductions in total testosterone following a carbohydrate supplement have been reported in resistance-trained men [6].

The findings related to the catabolic hormone cortisol are somewhat similar to those for testosterone. That is, cortisol has been shown to significantly decrease following ingestion of a high fat meal in healthy men $[4,17]$. However, the literature is not in agreement with regards to the cortisol response to a high carbohydrate meal. Some investigations demonstrate significant increases in cortisol following high carbohydrate meals in healthy men [4], as well as in women with abdominal obesity
[16]. This could potentially be due to the finding of increased insulin and subsequent decreased blood glucose-which in response may stimulate an increase in cortisol in an attempt to maintain glucose homeostasis [22]. Other studies note non-significant changes in cortisol with carbohydrate feeding in resistance-trained men [6], and in healthy women [16]. Such discrepancies may be a function of subject population [16], meal size, and carbohydrate type (e.g., complex versus simple) [23]. Moreover, a potential confound in this work is the fact that some studies involve an initial blood sample obtained in a fasted state $[6,16]$, while others include a breakfast meal prior to obtaining the initial blood sample, which is then obtained close to mid-day when the actual test meal is administered [4,24]. Having a fundamental understanding of the circadian rhythm of both cortisol and testosterone [25,26], it appears important to obtain baseline blood samples in the morning while subjects are in a fasted state.

In the present investigation we compared the hormonal response to lipid and carbohydrate meals of different caloric content during the acute postprandial period. We hypothesized that the carbohydrate meals would result in the greatest increase in serum insulin, while the lipid meals would result in the greatest decrease in serum cortisol. These effects would be dependent on meal size (larger meals $=$ greater response). We believed that the response for testosterone would be similar between meals-and would decrease during the postprandial period.

\section{Methods}

\section{Subjects and Screening}

Ten young, healthy men were initially recruited from the University of Memphis campus and Memphis community. One subject dropped from the study prior to completing all four meals testing days due to a loss of interest. The sample size was chosen based on prior work in this area of study using similar outcome variables, in particular with a cross-over design. All subjects were non-smokers, of normal body weight, normolipidemic (fasting triglycerides $<200 \mathrm{mg} \cdot \mathrm{dL}^{-1}$ ), non-diabetic (fasting glucose $<126 \mathrm{mg} \cdot \mathrm{dL}^{-1}$ ), with no history of diagnosed cardiovascular or metabolic disorders. Subject descriptive characteristics are presented in Table 1.

During the initial visit to the lab, health history, medication and dietary supplement usage, and physical activity questionnaires were completed by subjects. The height, weight, and body composition of each subject was measured using a stadiometer, digital scale, and Lange skin fold calipers (via 7 site skinfold test and use of the Siri equation for estimating body density), respectively. Heart rate (via palpation) and blood pressure (via auscultation) were recorded following a 10 minute period of quiet rest. An explanation of dietary data recording was provided, 
Table 1 Characteristics of 9 men.

\begin{tabular}{ll}
\hline Variable & Value \\
\hline Age $(\mathrm{yrs})$ & $22 \pm 2$ \\
Height $(\mathrm{cm})$ & $181 \pm 8$ \\
Weight $(\mathrm{kg})$ & $82 \pm 12$ \\
BMI $\left(\mathrm{kg} \cdot \mathrm{m}^{-2}\right)$ & $25 \pm 4$ \\
Body fat $(\%)$ & $19 \pm 7$ \\
Waist $(\mathrm{cm})$ & $84 \pm 9$ \\
Hip $(\mathrm{cm})$ & $103 \pm 6$ \\
Resting heart rate $(\mathrm{bpm})$ & $68 \pm 10$ \\
Resting SBP $(\mathrm{mmHg})$ & $117 \pm 6$ \\
Resting DBP $(\mathrm{mmHg})$ & $66 \pm 9$ \\
\hline
\end{tabular}

Data are mean \pm SD.

along with data collection forms. Each subject was informed of all procedures, potential risks, and the benefits associated with the study. This was done through verbal and written form in accordance with the approved procedures of the University Institutional Review Board for Human Subjects Research and subjects provided written informed consent.

\section{Meal Testing}

Subjects reported to the lab in the morning following a 10-hour overnight fast. The time of day for each subject was similar for all testing sessions in an attempt to control for diurnal variation in serum hormones. Upon arrival, subjects rested for 10 minutes and then a pre-meal blood sample was collected. On four different days, using a random order cross-over design, and separated by 3-7 days, subjects consumed one of four meals: dextrose at 75 grams (300 calories), dextrose at 150 grams (600 calories), lipid at 33 grams (300 calories), lipid at 66 grams (600 calories). The dextrose was delivered in powder form (NOW Foods, Bloomingdale, IL; 100\% carbohydrate kcal; 100\% sugar) mixed in water and the lipid consisted of heavy whipping cream (standard dairy grade; $100 \%$ fat kcal; $60 \%$ saturated fat, $30 \%$ monounsaturated fat, $10 \%$ polyunsaturated fat). We chose dextrose and whipping cream in an attempt to specifically include both pure carbohydrate and pure lipid. We have noted in our past studies that both drinks are fairly well tolerated by subjects; this was also the case in the present study. All drinks contained water, as follows: the $300 \mathrm{kcal}$ drinks contained a total of $350 \mathrm{~mL}$ of fluid and the $600 \mathrm{kcal}$ drinks contained a total of $700 \mathrm{~mL}$ of fluid. The amount of dextrose powder and whipping cream was weighed (laboratory grade balance) and measured prior to the mixing of each drink. The volume of water added to each drink (in order to bring the total volume to $350 \mathrm{~mL}$ or $700 \mathrm{~mL}$ ) was measured in a graduated cylinder. All portions were mixed in a blender. Subjects were then provided $10 \mathrm{~min}$ utes to consume the assigned drink.
It should be noted that no placebo condition (no food) was provided in this investigation. This was partly due to the fact that the hormonal response to acute fasting is well described, with insulin remaining relatively stable over time [25], and both testosterone [26] and cortisol [25] falling during the morning hours. In addition, we have data from pilot work using a sample of 5 healthy men (mean age: $25 \mathrm{yrs}$ ), in which subjects reported to the lab in the morning hours in a 10 hour fasted state and remained fasted for a period of three hours so that blood could be collected and analyzed for insulin, testosterone, and cortisol. Our data from this pilot experiment corroborate the published findings. We have presented these pilot data in Figure $1 \mathrm{~B}, 2 \mathrm{~B}$, and $3 \mathrm{~B}$, simply to use for visual comparison.

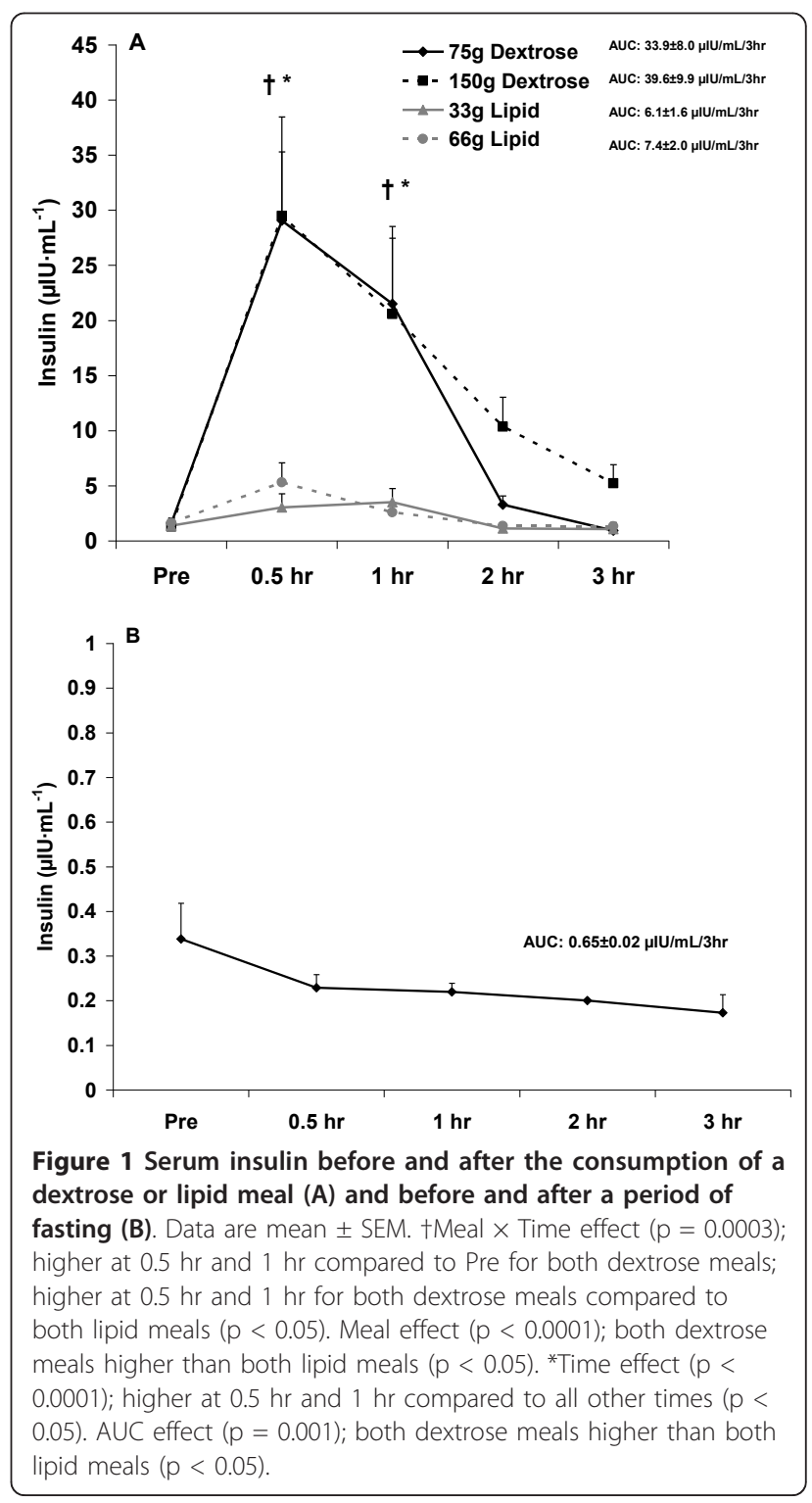




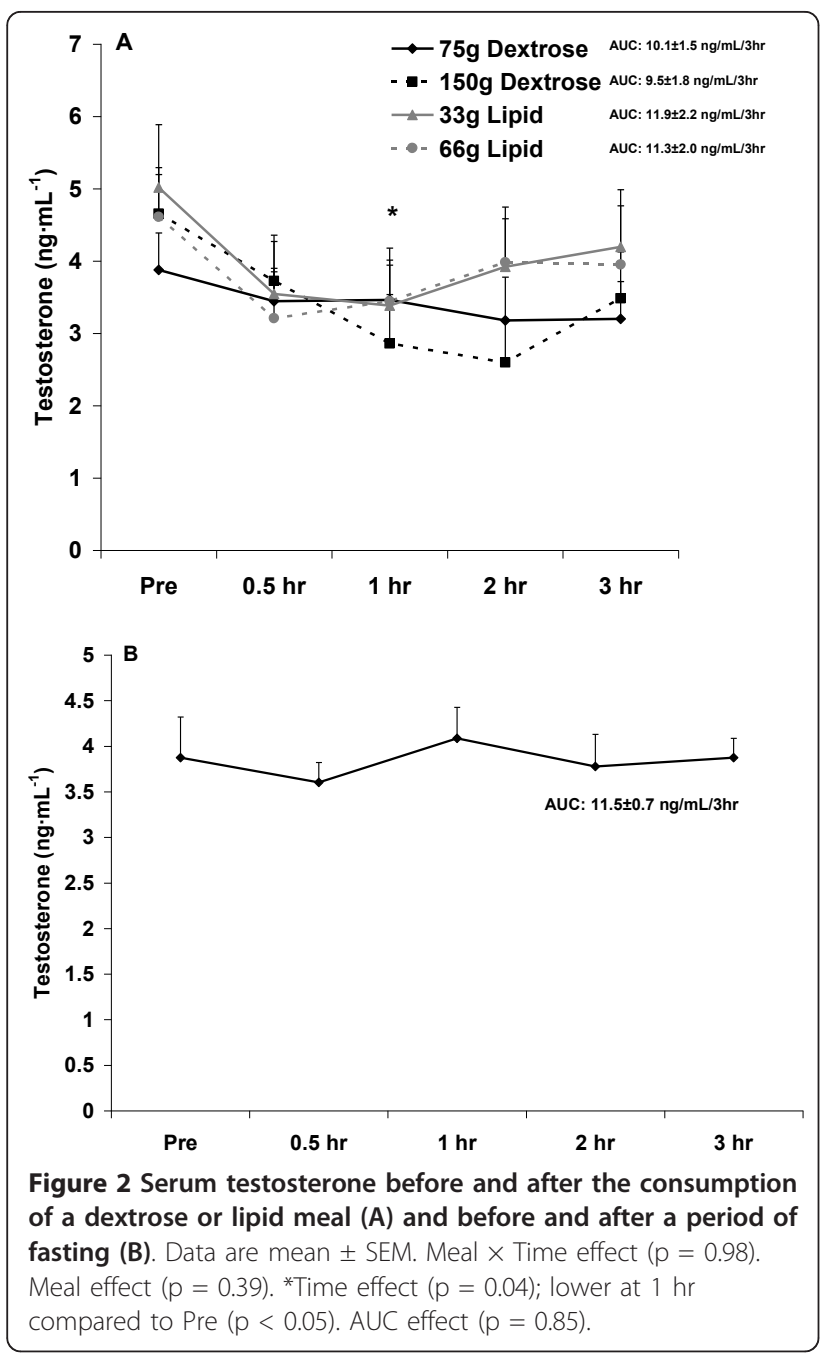

The postprandial observation period lasted three hours, during which time four additional blood samples were collected $(0.5 \mathrm{hr}, 1 \mathrm{hr}, 2 \mathrm{hr}$, and $3 \mathrm{hr})$. Subjects remained in the lab or in close proximity during this period and expended very little energy (i.e., watched movies, worked on the computer, read). No other meals or calorie containing beverages were allowed during this period. Water was allowed ad libitum during the first test day and matched for all subsequent test days.

\section{Blood Collection and Biochemistry}

Blood samples were obtained from subjects' forearm vein via needle and Vacutainer ${ }^{\circledR}$. Following collection, blood samples were allowed to clot at room temperature for 30 minutes and then processed in a refrigerated centrifuge $\left(2000 \mathrm{~g}\right.$ for $15 \mathrm{~min}$ at $4^{\circ} \mathrm{C}$ ) in order to obtain serum. Serum samples were stored at $-70^{\circ} \mathrm{C}$ until analyzed for hormones of interest. Insulin, testosterone, and cortisol were all analyzed using enzyme linked immunosorbent

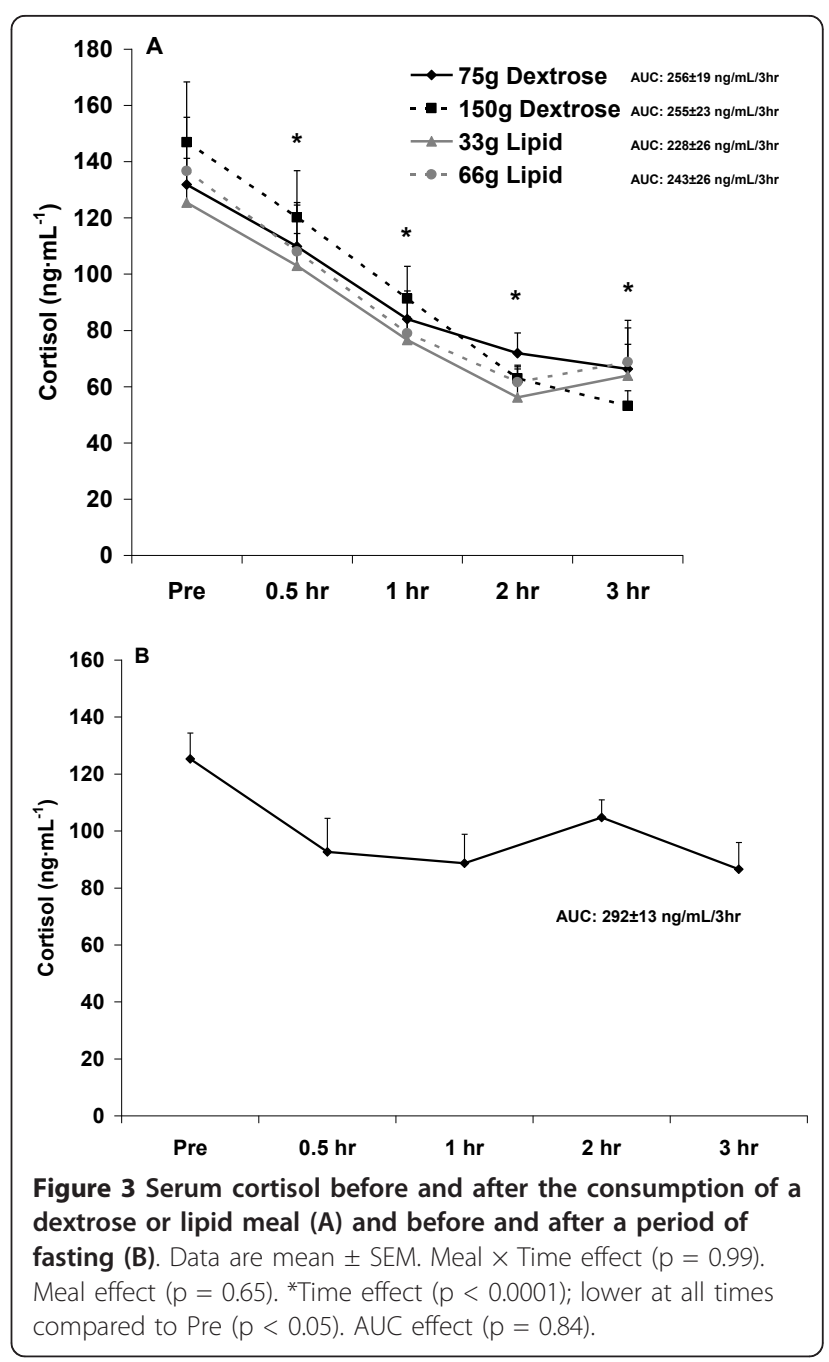

assay (ELISA) techniques according to the manufacturer (Calbiotech, Spring Valley, CA).

\section{Dietary Records}

Subjects were asked to maintain their normal diet and to record all food and beverage intake during the 24 hour period prior to each test day. Nutritional records were analyzed for total kilocalories, protein, carbohydrate, fat, vitamin C, vitamin E, and vitamin A (Food Processor SQL, version 9.9, ESHA Research, Salem, OR). Subjects were also asked to maintain their normal physical activity habits during the study period but to avoid strenuous exercise during the 24 hours preceding each test day.

\section{Statistical Analysis}

For each hormone, the area under the curve (AUC) was calculated using the trapezoidal method as described by Pruessner et al. [27]. In addition, data were analyzed using a 4 (meal) $\times 5$ (time) repeated measures analysis 
of variance (ANOVA). Significant interactions and main effects were further analyzed using Tukey's post hoc tests. Dietary variables were analyzed using a one-way ANOVA. All analyses were performed using JMP statistical software (version 4.0.3, SAS Institute, Cary, NC). Statistical significance was set at $\mathrm{P} \leq 0.05$. The data are presented as mean \pm SEM, except for subject descriptive characteristics which are presented as mean \pm SD.

\section{Results}

Nine subjects successfully completed all meal testing. No statistically significant differences were noted for kilocalories $(p=0.34)$, grams of protein $(p=0.87)$, grams of carbohydrate $(\mathrm{p}=0.50)$, grams of fat $(\mathrm{p}=$ $0.53)$, vitamin $C(p=0.76)$, vitamin $E(p=0.85)$, or vitamin A ( $1=0.73)$. Dietary data are presented in Table 2.

With regards to insulin, a meal $\times$ time effect $(\mathrm{p}=$ 0.0003 ) was noted, with values higher at $0.5 \mathrm{hr}$ and $1 \mathrm{hr}$ compared to Pre meal for both $75 \mathrm{~g}$ and $150 \mathrm{~g}$ dextrose meals, and higher at $0.5 \mathrm{hr}$ and $1 \mathrm{hr}$ for dextrose meals compared to lipid meals ( $\mathrm{p}<0.05)$. A meal effect was also noted for insulin ( $\mathrm{p}<0.0001)$, with both dextrose meals higher than lipid meals $(\mathrm{p}<0.05)$. Finally, a time effect was noted for insulin $(\mathrm{p}<0.0001)$, with values higher at $0.5 \mathrm{hr}$ and $1 \mathrm{hr}$ compared to all other times $(\mathrm{p}<0.05)$. The AUC for insulin ( $\mathrm{p}=0.001$ ) was higher for both dextrose meals compared to the lipid meals $(p<0.05)$. Insulin data are presented in Figure 1.

With regards to testosterone, no interaction $(\mathrm{p}=0.98)$ or meal ( $p=0.39)$ effect was noted. However, a time effect was noted ( $\mathrm{p}=0.04)$, with values decreasing during the postprandial period and being statistically lower at $1 \mathrm{hr}$ compared to Pre meal $(\mathrm{p}<0.05)$. No AUC effect was noted for testosterone $(\mathrm{p}=0.85)$. Testosterone data are presented in Figure 2.

With regards to cortisol, no interaction $(\mathrm{p}=0.99)$ or meal $(p=0.65)$ effect was noted. However, a time effect was noted $(\mathrm{p}<0.0001)$, with values lower at all times

Table 2 Dietary data of 9 men during the 24 hours before intake of a dextrose or lipid meal.

\begin{tabular}{lcccc}
\hline Variable & $\begin{array}{c}\text { Dextrose } \\
\mathbf{7 5} \mathbf{~ g}\end{array}$ & $\begin{array}{c}\text { Dextrose } \\
\mathbf{1 5 0 ~ g}\end{array}$ & $\begin{array}{c}\text { Lipid } \\
\mathbf{3 3 ~ g}\end{array}$ & $\begin{array}{c}\text { Lipid } \\
\mathbf{6 6 ~ g}\end{array}$ \\
\hline Kilocalories & $2023 \pm 237$ & $2354 \pm 242$ & $1983 \pm 206$ & $1789 \pm 181$ \\
Protein (g) & $92 \pm 11$ & $102 \pm 9$ & $95 \pm 13$ & $88 \pm 16$ \\
Carbohydrate (g) & $261 \pm 39$ & $315 \pm 41$ & $248 \pm 31$ & $247 \pm 33$ \\
Fat (g) & $72 \pm 11$ & $81 \pm 12$ & $72 \pm 13$ & $57 \pm 9$ \\
Vitamin C (mg) & $64 \pm 26$ & $47 \pm 11$ & $40 \pm 7$ & $51 \pm 13$ \\
Vitamin E (mg) & $4 \pm 2$ & $4 \pm 1$ & $3 \pm 1$ & $3 \pm 1$ \\
Vitamin A (RE) & $267 \pm 82$ & $374 \pm 110$ & $228 \pm 113$ & $236 \pm 102$ \\
\hline
\end{tabular}

Data are mean \pm SEM.

No statistically significant differences noted for kilocalories $(p=0.34)$, protein $(p=0.87)$, carbohydrate $(p=0.50)$, fat $(p=0.53)$, vitamin $C(p=0.76)$, vitamin $E(p=0.85)$, or vitamin $A(p=0.73)$. during the postprandial period as compared to Pre meal $(\mathrm{p}<0.05)$. No AUC effect was noted for cortisol ( $\mathrm{p}=$ 0.84). Cortisol data are presented in Figure 3.

Although we did not include a "no food" placebo condition in the present design, we have conducted a pilot experiment in which blood was collected from 5 healthy men at the same times as in the present study, while men remained fasting, and analyzed for the hormones of interest. When comparing findings from the present study to those of the pilot experiment, the following are noted: Insulin values were relatively unchanged in response to the no food condition (Figure 1B) and although no increase of statistical significance was noted with the lipid meals, values for insulin did increase slightly, in a dose dependent manner (Figure 1A).

The noted decrease in testosterone (Figure 2A), which was not different between meals, is not observed in the fasted state (Figure 2B). However, for cortisol the decrease is more pronounced with feeding (Figure 3A), as values are relatively stable between $0.5 \mathrm{hr}$ and $3 \mathrm{hr}$ when fasting (Figure 3B). This may be related to the rise in cortisol during a fasting period in an attempt to maintain blood glucose [25]. Collectively, it appears that feeding with either lipid or carbohydrate is associated with a decrease in circulating testosterone and cortisol, without differences noted between meals.

\section{Discussion}

Findings from the present study indicate that 1) little difference is noted in serum testosterone or cortisol during the acute postprandial period when healthy men consume lipid and dextrose meals of different size; 2) Both testosterone and cortisol experience a drop during the acute postprandial period (regardless of the meal consumed; regardless of the insulin response), which is similar to what is observed during an acute fasting state and follows the normal diurnal variation of these hormones; 3) dextrose meals of either $75 \mathrm{~g}$ or $150 \mathrm{~g}$ result in a significant increase in serum insulin, in particular at $0.5 \mathrm{hr}$ and $1 \mathrm{hr}$ post-ingestion; 4) lipid meals have little impact on serum insulin during the acute postprandial period.

Considered collectively, ingestion of either carbohydrate (in the form of dextrose) or lipid (in the form of heavy whipping cream) does not differently impact the hormonal response to feeding, as measured by serum testosterone and cortisol. However, serum insulin is largely impacted by dextrose feeding, as was expected based on the acute rise in serum glucose that occurs with such feeding [28]. While the increase in circulating insulin may be viewed as welcome for some individuals (e.g., active individuals attempting to resynthesize muscle glycogen [29] or favoring the anabolic activity of insulin [30]), chronic ingestion of high quantities of 
simple sugar may not be optimal for overall health, as it may lead to weight gain [31], impaired insulin sensitivity [32], and other untoward effects [33] in certain individuals.

Cortisol decreased to a similar extent following carbohydrate and lipid meals, despite a drastically different insulin response. While some authors have reported no change in cortisol following a high carbohydrate meal in active and sedentary men $[2,6,16]$, others have noted significant increases in cortisol, in particular when compared to meals rich in fat $[4,16]$. Martens et al. noted that when healthy men consume a carbohydrate meal consisting of $18 \%$ of daily energy requirements, a significant increase in cortisol is observed when compared to a fat and protein meal of similar hedonic values [4]. It has been postulated that this relative increase in cortisol following carbohydrate feeding occurs due to the ensuing stress resulting from a spike in blood glucose, and the subsequent rise in serotonin, which then leads to an increase in cortisol [4].

Our findings, as well as those of others [6,16], do not support an increase in cortisol in healthy men and women consuming a high carbohydrate meal-possibly due to more tightly regulated blood glucose control in a population of healthy individuals. However, Vicennati and colleagues demonstrated an increase in cortisol when women with abdominal obesity consumed a high (89\%) carbohydrate meal, as well as after consumption of a mixed protein/lipid meal (43\% protein and $53 \%$ lipid) in women with peripheral obesity [16]. While we noted no differences in postprandial cortisol response regardless of meal type or size, our subjects were young and healthy men and consumed only an isolated morning meal. As with many aspects of human nutrition, differences in subject population may impact findings.

To our knowledge, no other studies have investigated the effects of different macronutrients, provided at different caloric values, on insulin, testosterone, and cortisol. Aside from insulin, which increases significantly in response to carbohydrate but not lipid ingestion, no differences were noted in testosterone or cortisol in response to macronutrient ingestion of different type or meal size. Specifically, both testosterone and cortisol decreased in a pattern that follows the normal diurnal variation in these hormones. As discussed above, our results for cortisol agree with some prior reports, while our findings for decreased testosterone following meals rich in carbohydrate $[2,10,11]$ and fat $[14,17]$ are also supported. A finding of interest in the present study is the fact that the response for these hormones does not differ based on caloric content of the meal.

Although we did not make a direct comparison between our findings with the four meals and those involving a fasting condition, the drop in testosterone (Figure 2) and cortisol (Figure 3) with feeding appears more pronounced than with fasting. For testosterone, this may be viewed as negative, as increased levels of testosterone would be favored during the postprandial period to allow for anabolism [34]. For cortisol, a further lowering during the postprandial period may be viewed as positive, as lower cortisol may be associated with decreased proteolysis [35]-also important when considering anabolism. However, despite these findings, no differences existed for meal type or size with regards to testosterone or cortisol. With regards to cortisol and the further reduction of this hormone following meal consumption as compared to when in a fasted state, a calorie load of some unknown and relatively small value may be adequate to minimize the rise in this hormone-which may be in direct response to a drop in blood glucose and an attempt for cortisol to assist in maintaining glycemia while in a fasted state [22].

Admittedly, we do not fully understand what such acute changes in hormone concentrations mean as related to overall health and muscle tissue growth. Clearly, testosterone has been reported to increase following exercise [36], and is believed to be a major contributor to muscle mass gain [37]. It is logical to assume that elevated testosterone may equate to a greater degree of muscle growth over time; hence, methods of increasing testosterone via food intake appear appropriate. However, when exercise is followed by the consumption of carbohydrate and/or protein, testosterone values fall below resting levels in resistance-trained men $[38,39]$. This drop in testosterone is not observed in trained men who consume a placebo following exercise [6,39]. Despite the potential drop in testosterone during the acute postprandial period, carbohydrate/protein supplementation occurring two hours before exercise and immediately post-exercise, results in a peak of serum insulin concentrations by $500 \%$ above resting values within 45 minutes of ingestion [39]. Considering the multiple components and systems involved in regulating both anabolic and catabolic processes, the acute changes in circulating hormones from macronutrient consumption must be viewed with caution. That is, although testosterone may be acutely decreased with feeding, avoiding the ingestion of nutritious foods (in particular, post-exercise) may prove counterproductive with regards to influencing other anabolic hormones (e.g., insulin), as well as other aspects of human health and recovery (e. g., cellular immunity, glycogen resynthesis).

It is important to note some limitations of this work. First, we used a sample of healthy men, with measurements obtained in a fasted state. It is possible that 
subjects with known disease, and/or women, may have responded differently. Second, testing was conducted in the morning hours, in an attempt to control for the diurnal variations in hormones, and measurements ceased three hours following meal ingestion. Different results may have been obtained if testing was conducted at a different time of day [4] and/or if measurements extended beyond the three hour post meal time $[1,12,13]$. Third, our study only involved the ingestion of isolated carbohydrate (in the form of dextrose) and lipid (in the form of heavy whipping cream) meals. The inclusion of protein meals [40], or mixed meals [1], may have resulted in different findings. Fourth, we only included a measure of total testosterone, and not free testosterone, which is the most biologically active state of testosterone comprising about $0.2-2 \%$ of total testosterone [34]. It is possible that free testosterone may have responded differently to feeding. Fifth, other hormones involved in anabolism and catabolism, such as growth hormone, were not measured. Measurement of additional hormones may have provided further insight into the impact of feeding on postprandial hormonal response. Finally, the inclusion of exercise within the research design could have introduced another variable which may have impacted our findings [6]. Further research in this area may consider the above limitations in order to improve upon the study design.

\section{Conclusions}

Our data indicate that acute feeding of either lipid or carbohydrate of varying size has little impact on serum testosterone or cortisol during the acute postprandial period. Serum insulin is significantly increased by carbohydrate feedings, but not lipid feedings. Future work should consider the inclusion of older and metabolically compromised individuals, as well as women, in an effort to determine their response to single macronutrient feeding of different loads. These studies may also consider the use of multiple meals of a particular macronutrient to gather data regarding how these hormones are affected during a 24 hour cycle. This would further clarify whether the changes in cortisol and testosterone are indeed impacted by feeding or if they simply follow their diurnal cycle.

\footnotetext{
Authors' contributions

RJA was responsible for literature review and manuscript preparation. RJB was responsible for the study design, biochemical work, statistical analyses, and manuscript preparation. Both authors read and approved of the final manuscript.
}

\section{Competing interests}

Financial support for this work was provided by the University of Memphis. The authors declare no competing interests.
Received: 22 June 2011 Accepted: 11 November 2011

Published: 11 November 2011

\section{References}

1. Habito RC, Ball MJ: Postprandial changes in sex hormones after meals of different composition. Metabolism 2001, 50:505-511.

2. Mikulski T, Ziemba A, Nazar K: Metabolic and hormonal responses to body carbohydrate store depletion followed by high or low carbohydrate meal in sedentary and physically active subjects. J Physiol Pharmacol 2010, 61:193-200.

3. El Khoury D, Hwalla N: Metabolic and appetite hormone responses of hyperinsulinemic normoglycemic males to meals with varied macronutrient compositions. Ann Nutr Metab 2010, 57:59-67.

4. Martens MJ, Rutters F, Lemmens SG, Born JM, Westerterp-Plantenga MS: Effects of single macronutrients on serum cortisol concentrations in normal weight men. Physiol Behav 2010, 101:563-567.

5. Meikle AW, Cardoso de Sousa JC, Hanzalova J, Murray DK: Oleic acid inhibits cholesteryl esterase and cholesterol utilization for testosterone synthesis in mouse Leydig cells. Metabolism 1996, 45:293-299.

6. Schumm SR, Triplett NT, McBride JM, Dumke CL: Hormonal response to carbohydrate supplementation at rest and after resistance exercise. Int J Sport Nutr Exerc Metab 2008, 18:260-280.

7. Haff GG, Lehmkuhl MJ, McCoy LB, Stone MH: Carbohydrate supplementation and resistance training. J Strength Cond Res 2003, 17:187-196.

8. Lambert EV, Speechly DP, Dennis SC, Noakes TD: Enhanced endurance in trained cyclists during moderate intensity exercise following 2 weeks adaptation to a high fat diet. Eur J Appl Physiol Occup Physiol 1994 69:287-293.

9. Stellingwerff $T$, Spriet $L L$, Watt MJ, Kimber NE, Hargreaves M, Hawley JA, Burke LM: Decreased PDH activation and glycogenolysis during exercise following fat adaptation with carbohydrate restoration. Am J Physiol Endocrinol Metab 2006, 290:E380-8.

10. Hjalmarsen A, Aasebo U, Aakvaag A, Jorde R: Sex hormone responses in healthy men and male patients with chronic obstructive pulmonary disease during an oral glucose load. Scand J Clin Lab Invest 1996, 56:635-640.

11. Ivandic A, Prpic-Krizevac I, Jakic M, Bacun T: Changes in sex hormones during an oral glucose tolerance test in healthy premenopausal women. Fertil Steril 1999, 71:268-273.

12. Khoury DE, Hwalla N, Frochot V, Lacorte JM, Chabert M, Kalopissis AD: Postprandial metabolic and hormonal responses of obese dyslipidemic subjects with metabolic syndrome to test meals, rich in carbohydrate, fat or protein. Atherosclerosis 2010, 210:307-313.

13. Lopez S, Bermudez B, Ortega A, Varela LM, Pacheco YM, Villar J, Abia R, Muriana FJ: Effects of meals rich in either monounsaturated or saturated fat on lipid concentrations and on insulin secretion and action in subjects with high fasting triglyceride concentrations. Am J Clin Nutr 2011, 93:494-499.

14. Meikle AW, Stringham JD, Woodward MG, McMurry MP: Effects of a fatcontaining meal on sex hormones in men. Metabolism 1990, 39:943-946.

15. van Oostrom AJ, van Dijk H, Verseyden C, Sniderman AD, Cianflone K, Rabelink TJ, Castro Cabezas M: Addition of glucose to an oral fat load reduces postprandial free fatty acids and prevents the postprandial increase in complement component 3. Am J Clin Nutr 2004, 79:510-515.

16. Vicennati V, Ceroni L, Gagliardi L, Gambineri A, Pasquali R: Comment: response of the hypothalamic-pituitary-adrenocortical axis to highprotein/fat and high-carbohydrate meals in women with different obesity phenotypes. J Clin Endocrinol Metab 2002, 87:3984-3988.

17. Volek JS, Gomez AL, Love DM, Avery NG, Sharman MJ, Kraemer WJ: Effects of a high-fat diet on postabsorptive and postprandial testosterone responses to a fat-rich meal. Metabolism 2001, 50:1351-1355.

18. Nuutila P, Peltoniemi P, Oikonen V, Larmola K, Kemppainen J, Takala T, Sipila H, Oksanen A, Ruotsalainen U, Bolli GB, Yki-Jarvinen H: Enhanced stimulation of glucose uptake by insulin increases exercise-stimulated glucose uptake in skeletal muscle in humans: studies using [150]O2, [15O]H2O, [18F]fluoro-deoxy-glucose, and positron emission tomography. Diabetes 2000, 49:1084-1091.

19. Floyd JC Jr, Fajans SS, Conn JW, Knopf RF, Rull J: Stimulation of insulin secretion by amino acids. J Clin Invest 1966, 45:1487-1502. 
20. Marques-Lopes I, Forga L, Martinez JA: Thermogenesis induced by a highcarbohydrate meal in fasted lean and overweight young men: insulin, body fat, and sympathetic nervous system involvement. Nutrition 2003, 19:25-29.

21. Dorgan JF, Judd JT, Longcope C, Brown C, Schatzkin A, Clevidence BA, Campbell WS, Nair PP, Franz C, Kahle L, Taylor PR: Effects of dietary fat and fiber on plasma and urine androgens and estrogens in men: a controlled feeding study. Am J Clin Nutr 1996, 64:850-855.

22. Gerich JE: Control of glycaemia. Baillieres Clin Endocrinol Metab 1993, 7:551-586.

23. Raben A, Kiens B, Richter EA: Differences in glycaemia, hormonal response and energy expenditure after a meal rich in mono- and disaccharides compared to a meal rich in polysaccharides in physically fit and sedentary subjects. Clin Physiol 1994, 14:267-280.

24. Lemmens SG, Born JM, Martens EA, Martens MJ, Westerterp-Plantenga MS: Influence of consumption of a high-protein vs. high-carbohydrate meal on the physiological cortisol and psychological mood response in men and women. PloS One 2011, 6:e16826.

25. Hojlund K, Wildner-Christensen M, Eshoj O, Skjaerbaek C, Holst JJ, Koldkjaer O, Moller Jensen D, Beck-Nielsen H: Reference intervals for glucose, beta-cell polypeptides, and counterregulatory factors during prolonged fasting. Am J Physiol Endocrinol Metab 2001, 280:E50-8.

26. Plymate SR, Tenover JS, Bremner WJ: Circadian variation in testosterone, sex hormone-binding globulin, and calculated non-sex hormone-binding globulin bound testosterone in healthy young and elderly men. J Androl 1989, 10:366-371.

27. Pruessner JC, Kirschbaum C, Meinlschmid G, Hellhammer DH: Two formulas for computation of the area under the curve represent measures of total hormone concentration versus time-dependent change. Psychoneuroendocrinology 2003, 28:916-931.

28. Fisher-Wellman KH, Bloomer RJ: Exacerbated postprandial oxidative stress induced by the acute intake of a lipid meal compared to isoenergetically administered carbohydrate, protein, and mixed meals in young, healthy men. J Am Coll Nutr 2010, 29:373-381.

29. Burke LM, Collier GR, Hargreaves M: Muscle glycogen storage after prolonged exercise: effect of the glycemic index of carbohydrate feedings. J Appl Physiol 1993, 75:1019-1023.

30. Erotokritou-Mulligan I, Holt RI: Insulin-like growth factor I and insulin and their abuse in sport. Endocrinol Metab Clin North Am 2010, 39:33-43, viii.

31. Mrdjenovic G, Levitsky DA: Nutritional and energetic consequences of sweetened drink consumption in 6- to 13-year-old children. J Pediatr 2003, 142:604-610.

32. Willett W, Manson J, Liu S: Glycemic index, glycemic load, and risk of type 2 diabetes. Am J Clin Nutr 2002, 76:274S-80S.

33. Brand-Miller JC, Holt SH, Pawlak DB, McMillan J: Glycemic index and obesity. Am J Clin Nutr 2002, 76:281S-5S.

34. Vingren JL, Kraemer WJ, Ratamess NA, Anderson JM, Volek JS, Maresh CM: Testosterone physiology in resistance exercise and training: the upstream regulatory elements. Sports Med 2010, 40:1037-1053.

35. Simmons PS, Miles JM, Gerich JE, Haymond MW: Increased proteolysis. An effect of increases in plasma cortisol within the physiologic range. J Clin Invest 1984, 73:412-420.

36. Hough JP, Papacosta E, Wraith E, Gleeson M: Plasma and salivary steroid hormone responses of men to high-intensity cycling and resistance exercise. J Strength Cond Res 2011, 25:23-31.

37. Kadi F: Cellular and molecular mechanisms responsible for the action of testosterone on human skeletal muscle. A basis for illegal performance enhancement. Br J Pharmacol 2008, 154:522-528.

38. Bloomer RJ, Sforzo GA, Keller BA: Effects of meal form and composition on plasma testosterone, cortisol, and insulin following resistance exercise. Int J Sport Nutr Exerc Metab 2000, 10:415-424.

39. Kraemer WJ, Volek JS, Bush JA, Putukian M, Sebastianelli WJ: Hormonal responses to consecutive days of heavy-resistance exercise with or without nutritional supplementation. J Appl Physiol 1998, 85:1544-1555.

40. Krezowski PA, Nuttall FQ, Gannon MC, Bartosh NH: The effect of protein ingestion on the metabolic response to oral glucose in normal individuals. Am J Clin Nutr 1986, 44:847-856.

doi:10.1186/1550-2783-8-19

Cite this article as: Alleman and Bloomer: Hormonal response to lipid and carbohydrate meals during the acute postprandial period. Journal of the International Society of Sports Nutrition 2011 8:19.

\section{Submit your next manuscript to BioMed Central and take full advantage of:}

- Convenient online submission

- Thorough peer review

- No space constraints or color figure charges

- Immediate publication on acceptance

- Inclusion in PubMed, CAS, Scopus and Google Scholar

- Research which is freely available for redistribution

Submit your manuscript at www.biomedcentral.com/submit
Biomed Central 